\title{
Vertical distribution of Petroleum Hydrocarbon in Jiaozhou Bay
}

\author{
Dongfang Yang ${ }_{1,2,3}^{1,}$, Youfu $\mathrm{Wu}^{1,2}$, Huozhong $\mathrm{He}^{1,2}$, Sixi $\mathrm{Zhu}^{1,2}$ and \\ Fengyou Wang ${ }^{1,2}$ \\ 1Research Center for Karst Wetland Ecology, Guizhou Minzu University, \\ Guizhou Guiyang, Guizhou Guiyang, China \\ 2College of Chemistry and Environmental Science, Guizhou Minzu \\ University, Shanghai, 550025, China \\ 3 North China Sea Environmental Monitoring Center, SOA, Qingdao \\ 266033, China \\ adfyang_dfyang@126.com
}

\begin{abstract}
Based on investigation dada on Petroleum Hydrocarbon (PHC) in April, August and November 1981 in Jiaozhou Bay, this paper analyzed the vertical distribution of PHC. Results showed that PHC contents were increasing from April and reaching the peak in August, and were decreasing in November. The distribution of PHC in bottom and surface waters were similar in April and August. Along with the decreasing of PHC content and the continuous sedimentation of PHC, the distribution of PHC in bottom and surface waters was inverse in November. The distribution of PHC in Jiaozhou Bay was determined by riverine input, water exchange and sedimentation.

Keywords: Petroleum Hydrocarbon; Vertical distribution; Source; Riverine input; Jiaozhou Bay

\section{Introduction}

PHC is one of the critial pollutant in marine environment, which is sourced from both natural and anthropogenic sources. Due to the rapid increase of petroleum producing and processing, ocean transportation, municipal runoff etc., PHC pollution in ocean had been serious problem [1]. Therefore, understanding the distribution and its seasonal variations of PHC is essential to marine environment protection and the maintaining of sustainable development of marine economy.

Jiaozhou Bay is a semi-closed bay, located in economic developed regions of Shandong province, eastern China. Previous studies showed that this bay had been polluted by PHC [2-3]. Based on investigation dada on Petroleum Hydrocarbon (PHC) in April, August and November 1981 in Jiaozhou Bay, this paper analyzed the vertical distribution of $\mathrm{PHC}$, and provided basis for pollution control and environmental remediation.
\end{abstract}




\section{Material and method}

Jiaozhou Bay $\left(35^{\circ} 55^{\prime}-36^{\circ} 18^{\prime} \mathrm{N}, 120^{\circ} 04^{\prime}-120^{\circ} 23^{\prime} \mathrm{E}\right)$ is located in the south of Shandong Province, eastern China (Fig. 1 and 2). It is a semi-closed bay, the bay mouth is only $3 \mathrm{~km}$ width. The total area and average water depth are $390 \mathrm{~km} 2$ and $7 \mathrm{~m}$ respectively. This bay has more than ten inflow rivers, including Haibo Rriver, Licun Rriver, Baisha Rriver, Dagu Rriver, and Loushan Rriver etc. All of rivers are seasonal rivers, and are input channels of various pollutants for PHC [2].

The data was provided by North China Sea Environmental Monitoring Center. The survey was conducted in April, August and November 1981. There were 31 monitoring sites in April, namely H34, A1, A2, A3, A4, A5, A6, A7, A8, B1, B2, B3, B4, B5, C1, C2, C3, C4, C5, C6, C7, C8, D1, D2, D3, D4, D5, D6, D7, D8 and D9 (Fig.1 and 2). In August, there were 38 monitoring sites, namely A1, A2, A3, A4, A5, A6, A7, A8, B1, B3, B4, B5, C1, C2, C3, C4, C5, C6, C7, C8, D1, D2, D3, D4, D5, D6, D7, D8, D9, H34, H35, H36, H37, H38, H39, H40 and H41 (Fig.1 and 2). In November, 8 monitoring sites namelyH34, H35, H36, H37, H38, H39, H40 and H41 were set up (Fig.1 and 2). PHC was monitored follow by National Specification for Marine Monitoring [4].

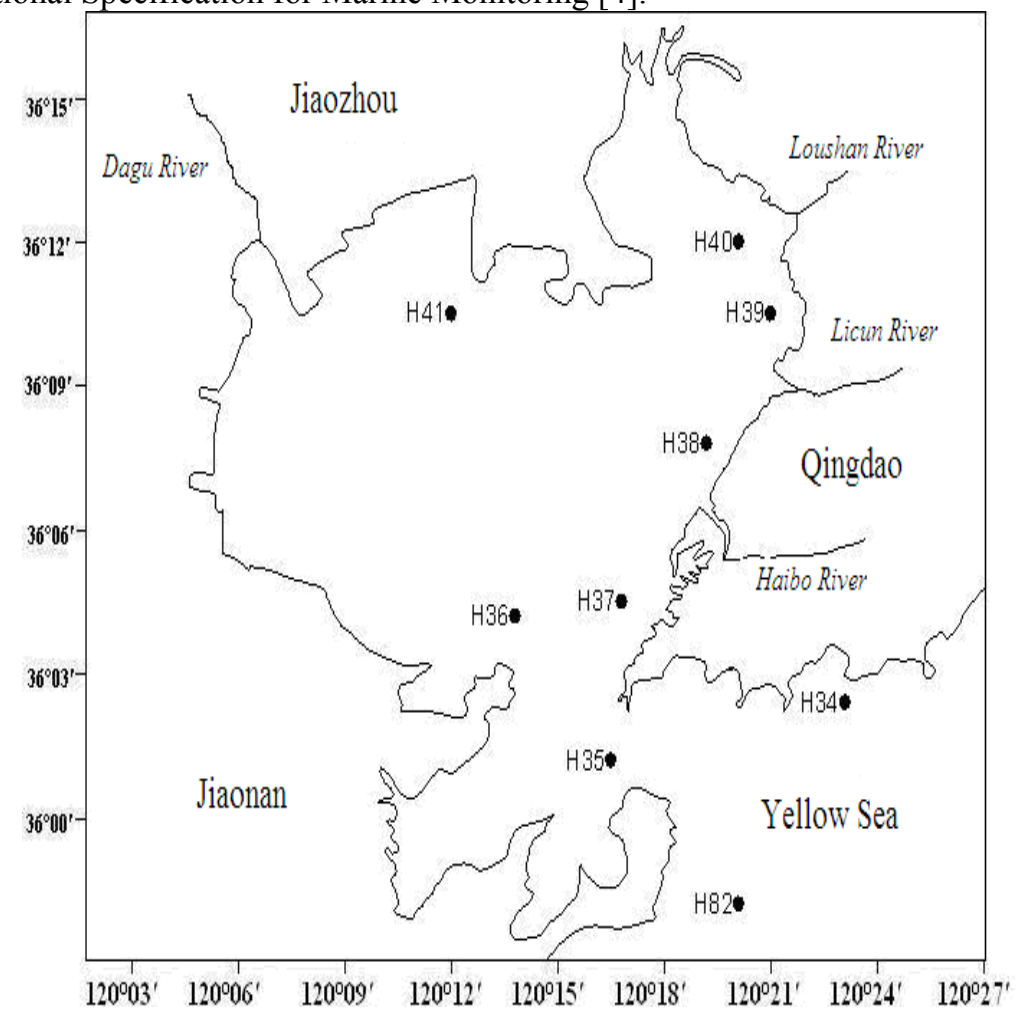

Fig.1 Monitoring sites $(\mathrm{H})$ in Jiaozhou Bay 


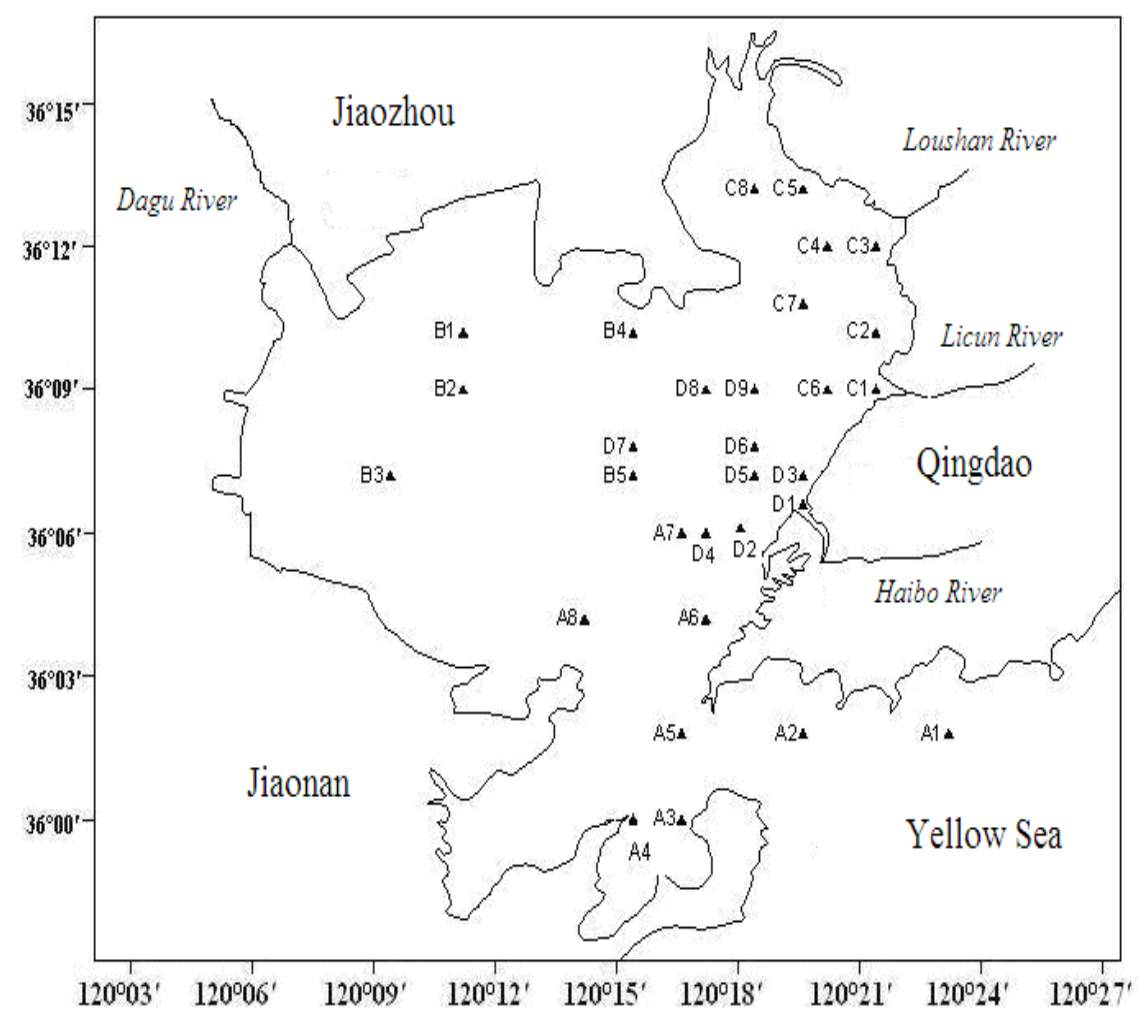

Fig.2 Monitoring sites (A and D) in Jiaozhou Bay

\section{Results and discussion}

Seasonal variation. We defined April, August and November as the representatives of spring, summer and autumn. The contents of PHC in both surface waters (Fig. 3) and bottom waters (Fig. 4) were rapidly increasing from spring to summer, and decreasing from summer to autumn. PHC contents in most of the monitoring sites in spring and summer were higher than $1 \mathrm{mg} \cdot \mathrm{L}^{-1}$, while in autumn, PHC contents in most of the monitoring sites were more lower. Source of PHC in Jiaozhou Bay were both point and non-point sources. The input of PHC form point source was relatively variable, while from non-point source was dependent of rainfall-runoff. Hence, form spring to summer, the precipitation in study area was increasing, and from summer to autumn was decreasing. 


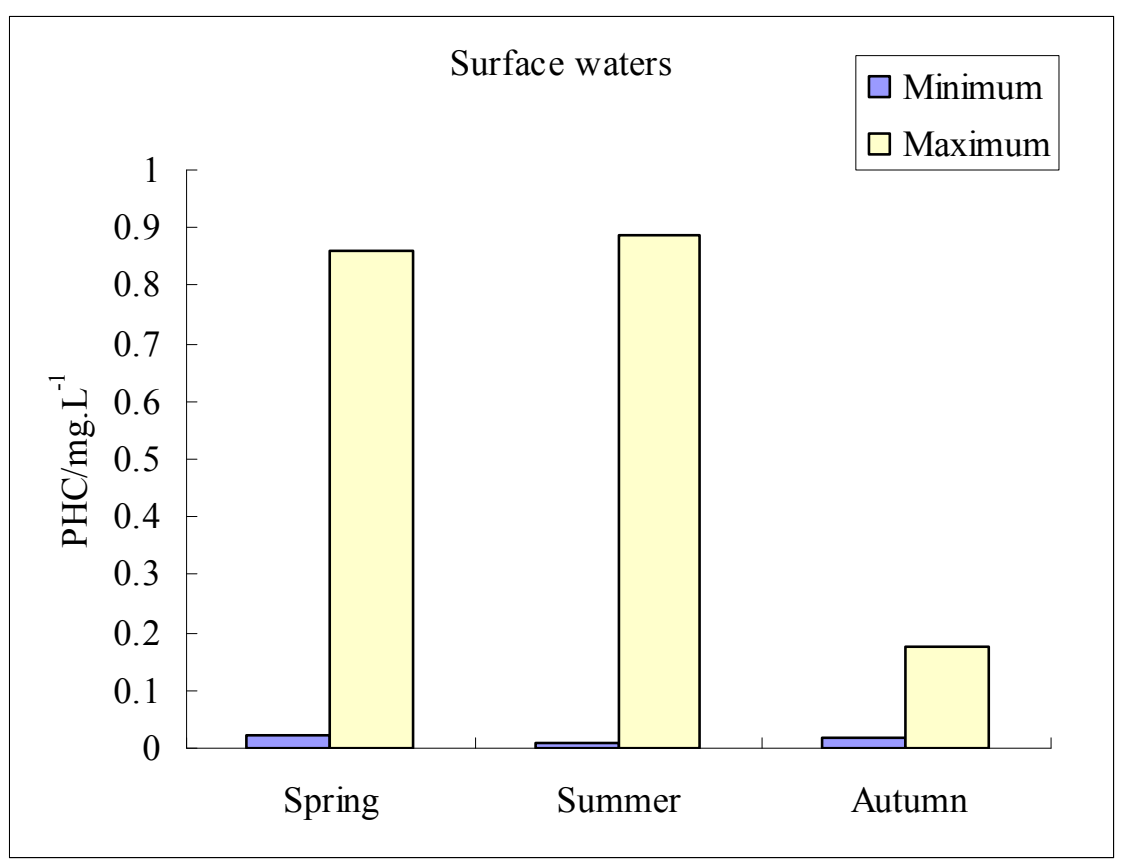

Fig.3 Seasonal variations of PHC contents in surface waters in Jiaozhou Bay

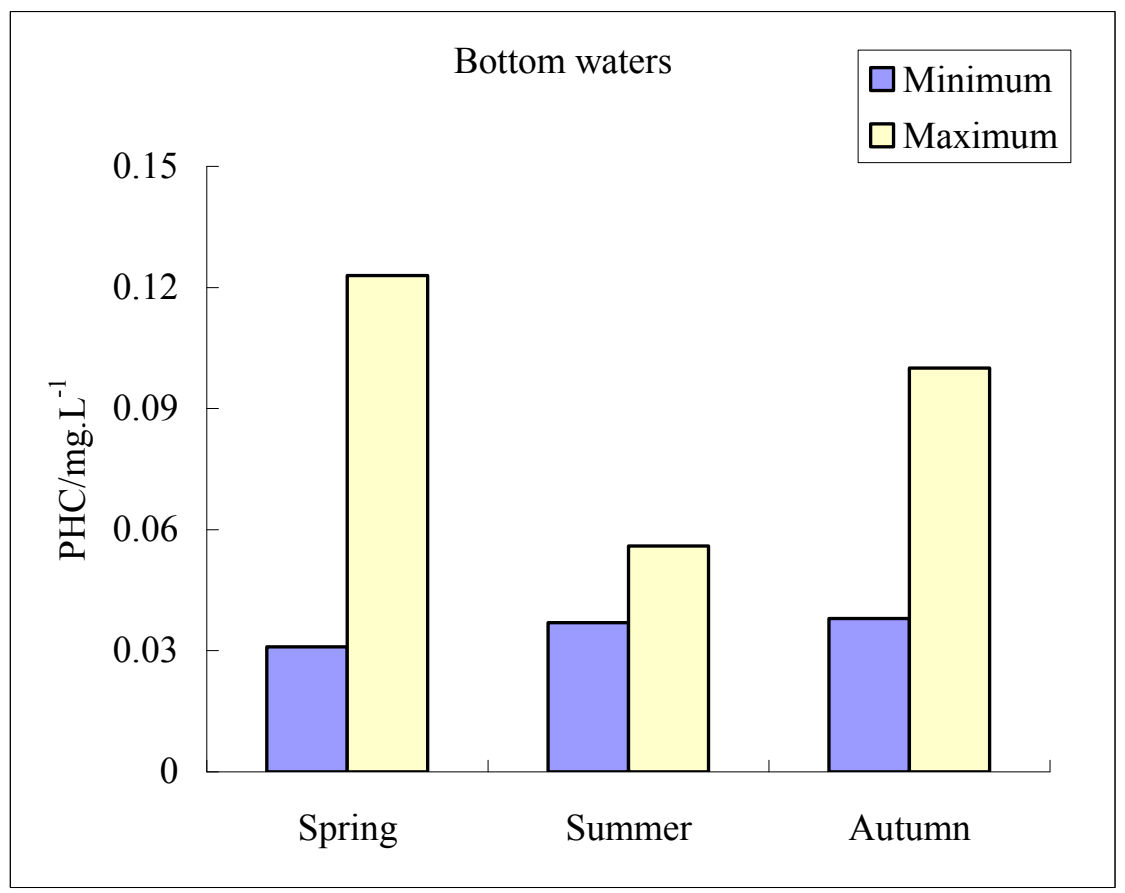

Fig.4 Seasonal variations of PHC contents in bottom waters in Jiaozhou Bay 
Vertical variation. The vertical variations of PHC contents in Jiaozhou Bay waters were showed in Fig. 5, by means of the subtractions of which in surface and bottom waters, in patterns of proportions of higher, lower and equal (Fig. 5). Within the 9 sampling sites in April, PHC contents in surface waters in 8 sites (A1, A2, A3, A6, A7, A8, D5 and H34) were higher than which in bottom waters, accounted for $88.9 \%$, and the remaining 1 site (A5) were lower than which in bottom waters, accounted for $11.1 \%$. Within the 13 sampling sites in August, PHC contents in surface waters in 4 sites $(\mathrm{A} 1, \mathrm{~A} 8, \mathrm{H} 34$ and $\mathrm{H} 36)$ were higher than which in bottom waters, 7 sites (A2, A3, A5, A7, B5, H35 and H37) were lower than which in bottom waters, and 2 sites (A6 and H37) were equal, accounted for $30.8 \%, 53.8 \%$, and $15.4 \%$, respectively. Within the 4 sampling sites in November, PHC contents in surface waters in 3 sites (H35, H36 and H37) were higher than which in bottom waters, accounted for $75.0 \%$, the remaining 1 site (H34) were lower than which in bottom waters, and accounted for $25.0 \%$.

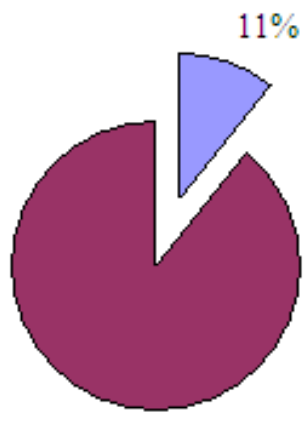

$89 \%$

(a) April

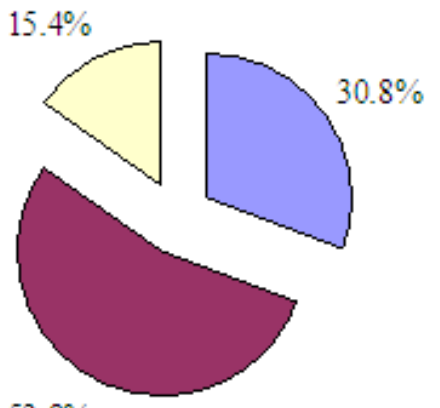

$53.8 \%$

(c) November

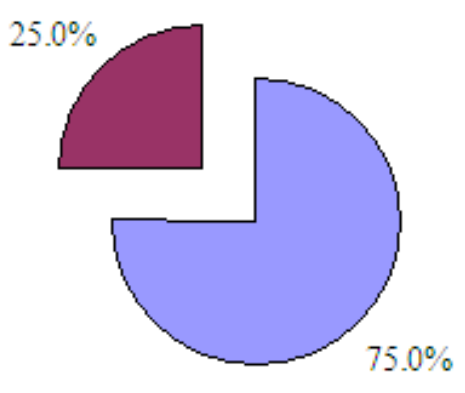

(b) August

\section{$\square$ Higher \\ $\square$ Lower \\ 口Equal}

Fig.5 Vertical variations of PHC contents in Jiaozhou Bay waters 
Sedimentation and accumulation. A comparison of the contents of PHC in the bay mouth and the bay center in surface waters was provided in Fig. 5. In April, August and November, PHC contents in surface waters were decreasing from the bay center to the bay mouth gradiently, and the highest and lowest values were 0.166 and $0.040 \mathrm{mg} . \mathrm{L}^{-1}, 0.056$ and $0.012 \mathrm{mg} . \mathrm{L}^{-1}$, and 0.068 and $0.041 \mathrm{mg} . \mathrm{L}^{-1}$, respectively. A comparison of the contents of PHC in the bay mouth and the bay center in bottom waters was provided in Fig. 6. In April and August, PHC contents in bottom waters were decreasing from the bay center to the bay mouth gradiently, and the highest and lowest values were 0.123 and $0.031 \mathrm{mg} . \mathrm{L}^{-1}$, and 0.056 and $0.037 \mathrm{mg} . \mathrm{L}^{-1}$, respectively. However, PHC contents in bottom waters were increasing from the bay center to the bay mouth in November, and the highest and lowest values were 0.100 and $0.038 \mathrm{mg} . \mathrm{L}^{-1}$. The PHC contents in the bay center in both surface and bottom waters were both higher than in the bay mouth in April and August, due to the PHC contents in bottom waters were mainly determined by which in surface waters by means of sedimentation. PHC is absorbable to particulate materials in sea waters [5], and therefore the absorption and sedimentation of PHC is able to transport PHC to the seafloor. Along with the continuously sedimentation of PHC as time went by, most of the PHC was accumulation in bottom waters, and than was transferred to the bay mouth by means of water exchange, so as the PHC contents in bottom waters was relative high in the bay mouth in November.

Aquatic transport process. Based on the vertical distribution and seasonal variation, we could reveal the aquatic transport process of PHC. Jiaozhou Bay is a semi-closed bay, water exchange is one of the major transport processes of various pollutants. Inflow rivers were channels for the input of PHC to the bay, and the PHC contents in areas closed to the river mouths were higher than in other areas. By means of water exchange and dilution, the PHC contents in various seasons in surface waters were decreasing from the center of the bay to the bay mouth. Sedimentation is one of the major processes. In spring and summer, due to the rapid sedimentation of PHC in spring and summer, the PHC contents in bottom waters were increasing, and were closed to that in surface waters. The input of PHC in autumn was decreasing; however, due to the accumulation of PHC in sediment, the distribution of PHC in bottom waters was inverse to that in surface waters. Above all, water exchange and sedimentation determined the transport processes of PHC in Jiaozhou Bay. 


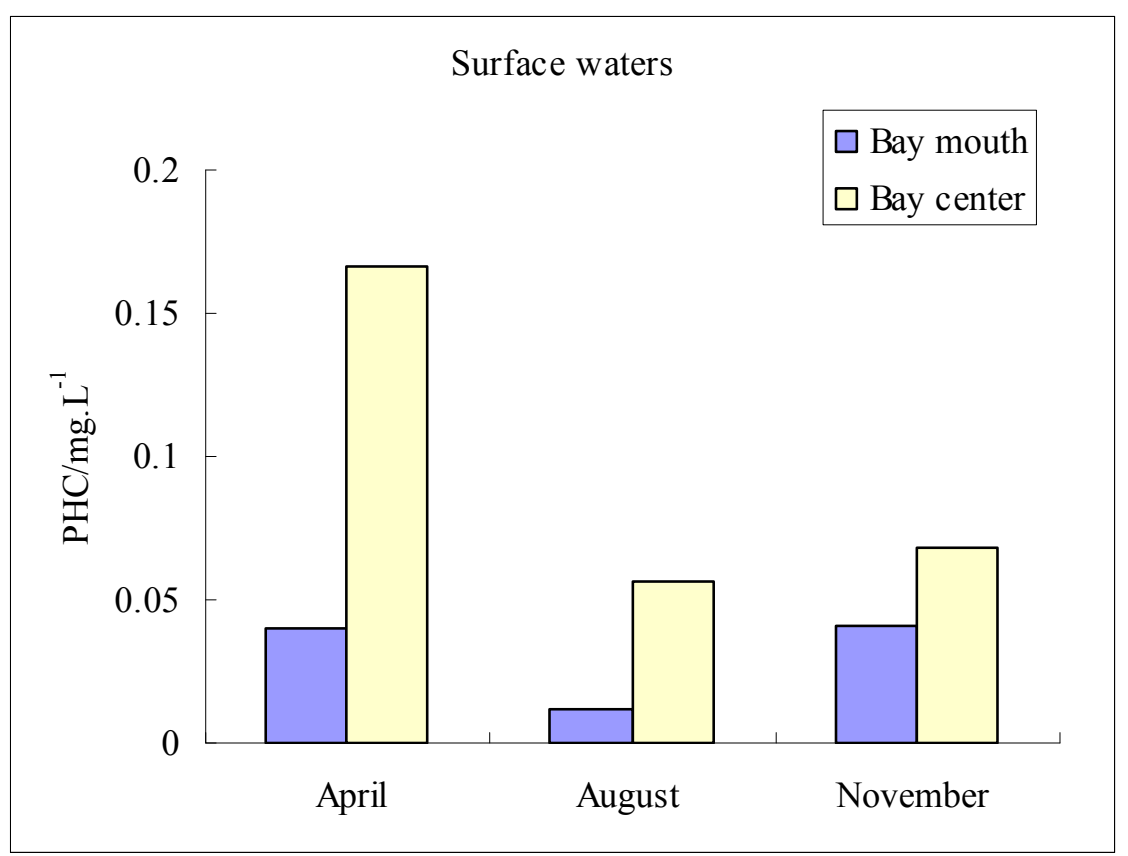

Fig.5 PHC contents in the bay center and the bay mouth in surface waters in Jiaozhou Bay

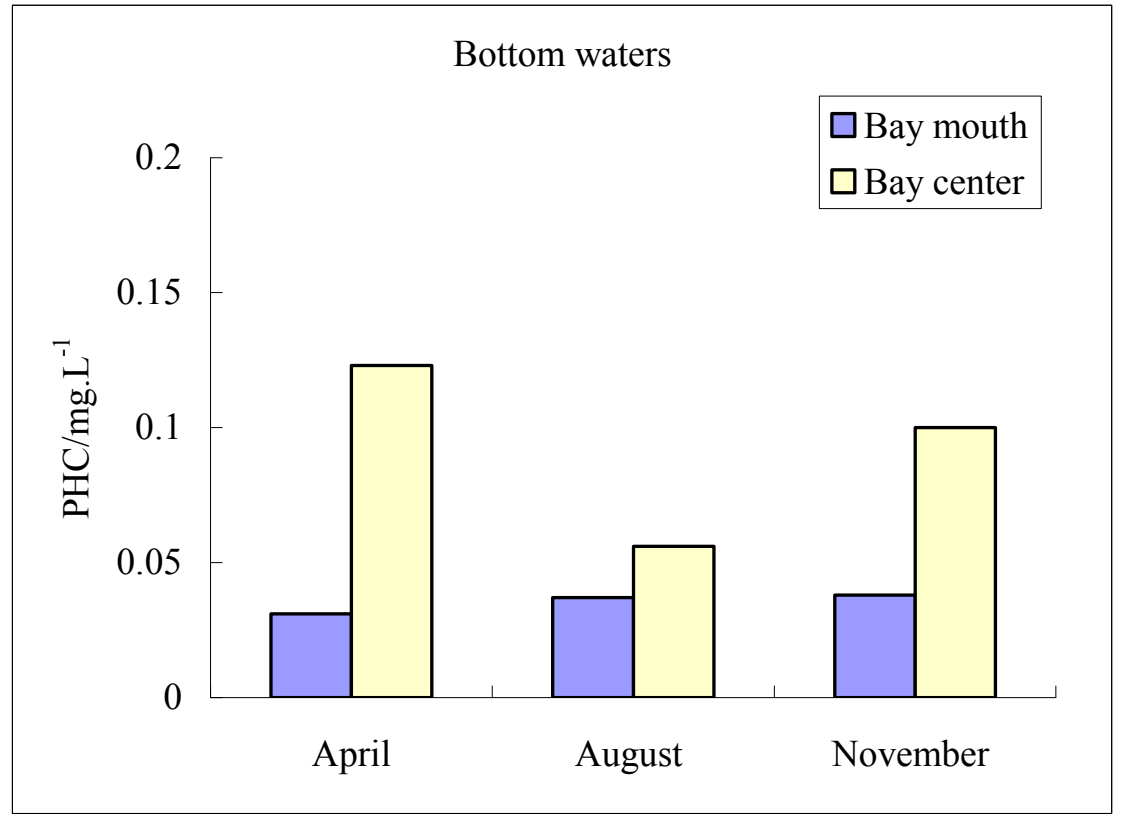

Fig.6 PHC contents in the bay center and the bay mouth in bottom waters in Jiaozhou Bay 


\section{Conclusion}

PHC contents were increasing from April and reaching the peak in August, and were decreasing in November. The distribution of PHC in bottom and surface waters were similar in April and August. Along with the decreasing of PHC content, and the continuous sedimentation of PHC, the distribution of PHC in bottom and surface waters was inverse November. The distribution of PHC in Jiaozhou Bay was determined by riverine input, water exchange and sedimentation.

\section{Acknowledgement}

This study was supported by Research project of Guizhou Province Department of Education: Development of intelligent monitor system of floaters in reservoirs ([2011]039), Research project of Guizhou Province Department of Science and Technology: Research on intelligent description of behaviors of trafic targets based on situational knowledge ([2011]2206), Special project for high-level talents of Guizhou Province: Development of intelligent monitor system of water pollution ([TZJF-2011]46), Research project of Guiyang: Research on intelligent trafic management system based on vision, Research project of Guizhou Province Department of Science and Technology: Development of intelligent monitor system of water pollution, Research project of Guiyang Bureau of Science and Technology: Development of intelligent monitor system of water pollution of Guiyang, and Research project of Guizhou Province Department of Education: Research on intelligent monitor platform of water resource quality of Guizhou based on information fusion ([2013]125).

\section{References}

[1] Zuqi Xiao. The underway of the offshore oil development of China [J]. Oil-Gasfield Surface Engineering,1987, 6(4): 50-52. (in Chinese)

[2] Dongfang Yang, Youchi Zhang, Jie Zou, Qing Zhou and Hailing Yang. Contents and distribution of petroleum hydrocarbons (PHC) in Jiaozhou Bay waters [J]. Open Journal of Marine Science, 2011, 2(3): 108-112.

[3] Dongfang Yang, Peiyan Sun, Chen Chen, Hongyan Bai and Qing Zhou. Distribution and pollution sources of petroleum hydrocarbons in Jiaozhou Bay [J]. Coastal Engineering, 2013, 32(1): 60- 72. (in Chinese)

[4] China's State Oceanic Administration: The specification for marine monitoring (Ocean Press, Beijing 1991), p.1-300. (in Chinese)

[5] D.F. Yang, F. Wang, Z.H. Gao, W.L. Cui and S.X. Huo: Mar. Sci., Vol. 28(2004),p.71-74. (in Chinese) 